\title{
How Can the Process of Adopting Energy Management in Organisations Inform Water Management Practice?
}

\author{
Marouane Azennoud, Richard Bull, Mark Lemon, and Darren Perry
}

\begin{abstract}
Energy and water are interconnected natural resources and are vital utilities utilised by organisations to enable their business delivery. Managing these resources within the United Kingdom ' $U K$ ' is currently focused on energy management with a small or neglected focus on water management in non-domestic buildings. This paper explores, through an overview of energy management policy, energy management practice, the water market and supported by a case study, the reasons for which the adoption of energy management should be encouraged in order to stimulate greater water management activity amongst organisations. The case study of Northamptonshire County Council is presented in order to illustrate energy management and water management activity in a high performing ISO50001:2011 organisation, demonstrating the authority's current approach to implementing water management and water efficiency projects. Results of this study show that, first, water management can be linked to energy management via the low emissions target for the UK. Second, that the lessons learned from the adoption of energy management by organisations are transferrable, and support a wider adoption of water management: i.e. policy enforcement, funding opportunities for water efficiency projects, etc.
\end{abstract}

Index Terms - Energy management, energy efficiency, water management, non-domestic building, metering.

\section{INTRODUCTION - RELATION BETWEEN ENERGY AND WATER: CASE OF UK}

Energy from natural resources and water are at the same time linked and dependent on one another [1], and, seemingly, independent when it comes to their management [2]. Water is a key resource for the energy generation industry [3]. Indeed, it is a source of multiple forms of energy production - for instance, electricity generation from hydropower where water is the primary source. And even in instances where it is not the primary source, its use is widespread within the generation of electricity from other sources such as coal, gas, fuel, solar thermal. In these cases, water is mainly used as coolant or in the form of steam as a driver of the turbines. Likewise, energy use is present in every step of water management: from pumping water to treatment plants; treating water to clean it and make it potable; distributing it to end users; and finally as part of the treatment process before waste water is returned to the water cycle [4]. However, there is little attention given to water management unlike energy management - this will be

Manuscript received August 25, 2016; revised November 15, 2016. This work was supported in part by Northamptonshire County Council.

M. Azennoud, R. Bull, M. Lemon are with De Montfort University, Leicester, LE1 9BH, UK (e-mail: p14187075@my365.dmu.ac.uk, rbull@dmu.ac.uk,mlemon@dmu.ac.uk).

D. Perry is with Northamptonshire County Council, Northampton, NN1 1DN, UK (email: Daperry@northamptonshire.gov.uk). discussed within this paper - and so this gives rise to a question of independency, or, disregard.

The first question to ask is: what is the extent to which energy management links to water management, and vice versa, within the United Kingdom 'UK'? It is stated that water management objectives in the UK are linked to national carbon and air quality objectives [5]: that is, water is used to generate energy; the production and distribution of water is energy and carbon intensive; and last, water is used to absorb pollutants emitted to the air - thus, all of which demanding the attention of policy. Moreover, although it is recognised that the water industry is only responsible for $1 \%$ of carbon emissions in the UK [5], decreasing the emissions associated with its use continues to form part of the UK's strategy for significantly reducing carbon emissions by 2050 [4]. Therefore, in the UK, water and energy are interdependent and linked through carbon emission objectives.

In order to decrease carbon emissions, first, water industry should rely more on new technologies that use energy with greater efficiency [4]. Second, to decrease energy usage within the energy sector, water demand should be controlled. This is related to the 'water-energy nexus'. In 2007, almost $25 \%$ of clean water produced in England and Wales was lost as a result of leakages and the water sector is energy intensive. This leads to important losses both in terms of energy and water [6] knowing that the energy use by the water sector in the UK increased by 4\% between 2009 and 2010 and that it takes $559 \mathrm{kWh}$ to clean $1 \mathrm{ML}$ of water [3]. "Saving water saves energy. Consequently, implementing integrated water management (IWM) measures that reduce potable water consumption, stormwater runoff, and wastewater generation can potentially translate into significant energy savings" [1]. Other examples of this interdependency can be seen with the effects of climate change, rain fall volumes and distributions, waste water treatment, etc.

All in all, energy and water are very linked. Water and indeed most natural resources are depleting, and managing them efficiently will help to conserve them for future generations by curving down the energy consumption [7]. However, there remains a question of how at the community level, as in homes or offices or schools, water management can become a common practice.

This paper will inform on how energy management is adopted in UK, water sector situation in the country, and -in the form of a case study- how water management and energy management can be interlinked.

\section{ENERGY MANAGEMENT IN WORK Place}

Energy Management has become a matter of interest in 
organisational management during the recent years, even though "Energy Management Systems have been extensively studied for almost 40 years" [8]. Seemingly, this interest has been necessitated by volatility in the prices of oil and other energy sources, as well as the enactment of new environmental policies by many countries, leaving companies and organisations with the only choice of decreasing emissions and lowering their operating costs in order to survive in highly competitive markets. "Users cannot control prices, politics, or the global economy, but they can manage how they use energy" [9].

From the following, companies and institutions in the UK have been driven to adopt energy efficiency and energy management through different regulations and reporting schemes. As an example, a new regulation called the Energy Saving Opportunity Scheme 'ESOS' came into force in July 2014 [10] as an implementation of article 8 of the EU Energy Efficiency Directive (2012/27/EU). The ESOS obliges all undertakings which fall within a defined scope to undertake an energy assessment and identification of potential energy saving schemes. In many ways, the ESOS could be considered the private sector equivalent to the Display Energy Certificate 'DEC' and the Advisory Report 'AR'- both of which are statutory requirements for public buildings with a gross internal area of $250 \mathrm{~m} 2$ or more and accessed by members of public. For instance, the ESOS excludes public undertakings but not public companies. Moreover, the process of issuing a valid $\mathrm{DEC}$ and $\mathrm{AR}$ requires the assessor to undertake an energy assessment of a public building and then an identification of energy saving opportunities. It should be noted that ESOS and DECs/ARs can be differentiated by the scope of the energy assessment, with ESOS requiring an assessment of greater breadth including for example transport considerations.

Another example, and through the UK's Carbon Plan to cut greenhouse gas 'GHG' emissions by $80 \%$ in 2050 compared to the levels of GHG emissions in 1990, the Carbon Reduction Commitment 'CRC' was launched in 2007 to help with achieving this [11]. Companies and institutions that fall within the CRC scope from both the public and private sector - with some never having previously faced an imposition of this nature [11] - are obliged to report and publish their carbon emissions yearly and to buy carbon allowances when they exceed thresholds.

Clearly and related to $\mathrm{CRC}$, there are three main incentives to adopt energy management and energy efficiency within organisations. The first one is that by reducing the carbon emissions, organisations will be out of scope for CRC and will not have to pay for carbon allowances. Second, the decrease in emissions will be achieved via a reduction in energy use or adoption of renewable energy generation technologies and therefore a decrease in costs. Third, companies will save any costs incurred by the procedure CRC compliance. CRC can be seen as a policy embodiment of the European Union Emissions Trading Scheme 'EU ETS', but for non-energy-intensive businesses or organisations which are not large entities.

However, how do organisations respond to these regulations?

With no doubt, such regulations push the top management in these organisations/companies to think about their emissions and energy use. As an example, and as stated previously, CRC targets some organisations which have never thought about their emissions and thus lack the expertise of how to manage their energies; unlike large companies which fall within the scope of EU ETS [11]. This encourages the adoption of energy management in their management strategies. Another example, found within article 5 of the directive 2012/27/EU, urges the public sector to implement energy management systems as part of their energy efficiency plans [12].

\section{What is Energy Management?}

It is difficult to find a definition of Energy Management without linking it to Management Systems which either relies on technologies or standards. Most of the academic papers found on online databases like IEEE, Scopus or Science Direct explain Energy Management as a part of the standard ISO50001:2011 or through the control devices/technologies used to command the flow of energies within the boundaries of a system be it a house or a factory or a line of production, etc. This leads Energy Management to appear like a technical skill [13].

In simple terms, Energy Management is about decreasing the cost of energies and minimising the carbon emissions of a company or an organisation [14]. Decreasing the cost can be achieved by procuring energy at cheaper prices and/or through decreasing the quantities of energy used. Different solutions and approaches can be used to help with establishing and integrating energy management in an organisation. As an example, standards like ISO50001:2011 helps in creating an organisational framework and a systematic approach (Plan-Do-Check-Act 'PDCA') to efficiently manage energy through the establishment of an energy policy, setting targets and goals, legal compliance, measuring the results, continual improvement, and other processes.

However, why water management is not adopted by small to medium non domestic consumers as it is the case for energy management?

\section{OVERVIEW OF THE WATER SECTOR IN UK}

\section{A. England and Wales}

The water industry in England and Wales has been privatised in 1989 resulting in 10 water and sewage companies and 9 water-only companies where each one has a geographical monopoly and are all appointed by OFWAT which is the economic regulator of the water sector in both countries [15]. The water and sewerage companies in England are private entities whereas in Wales, it is a company limited by guarantee [16]. Non domestic customers consuming more than 5 megalitres in England or 50 megalitres in Wales have the freedom to switch their water supply to any company licensed which falls under the Water Supply Licensing [15].

\section{B. Scotland}

The water industry in Scotland has been owned by the public sector. In 2002, three water authorities merged in into a 
public corporation called Scottish Water and which is responsible of the supply and retail of fresh water and the collection of the waste water. [17]. In 2008, the water market has been deregulated by separating between the wholesale and retail activities of Scottish Water allowing competition for water retail for non-domestic consumers. This has made Scotland the first country in the world to open the water and sewage market for all types of organisations [18]. The deregulation of the retail market has given the customers the opportunity to choose the best services that suits them - in the case study, it will be explained how this can help with water efficiency practices. It is believed that this measure will help in saving millions of pounds to costumers thanks to lower unit prices and lower water usage [18].

\section{Northern Ireland}

Following reforms in the water sector in Northern Ireland, a Government Owned Company "GoCo" called Northern Ireland Water Limited has been created and made the only water and sewerage operator.

\section{CASE STUdy: MOVES TO INTEGRATE ENERGY MANAGEMENT AND WATER MANAGEMENT IN SCHOOLS IN NORTHAMPTONSHIRE}

Northamptonshire County Council 'NCC' has been developing different solutions to decrease their energy consumption and emissions during the last 7 years. This has led to decrease NCC's emissions, from 90 tCO2 in 2010 to 50 tCO2 in 2015, and enabled it to unregister from CRC in 2014 saving the Council hundreds of thousands in CRC payments. Further evidence of activity in energy management can be seen in the financial savings accumulated by greater energy efficiency from the County Council and its customers. Though, how were these energy savings achieved and what were the motives for NCC to adopt energy management practices?

Traditionally, services within public authorities cost money. At a time of austerity and public sector cuts, there has been an urge to deliver services in the most efficient ways. Therefore, the Energy \& Carbon Management Team 'ECMT' in NCC has developed an energy business model, which generates a net income, saves the council millions of pounds and creates local investment and employment. The clear change in behaviour has transitioned from doing nothing, to proactively doing more, into an Energy Management System accredited to international standards (i.e. ISO 50001:2011) covering all organisational activities.

The ECMT has been procuring energy for the County Council and $90 \%$ of the schools in Northamptonshire; it has been noticed that the energy procured for schools constitutes the biggest share of the energy basket, hence why the ECMT has placed such importance on driving the energy consumption of Schools down through an energy efficiency programme. Those schools that purchase energy through the ECMT are entitled to a free energy survey/assessment, a DEC and an AR. The energy surveys and assessments have helped ECMT in building a database containing information about all the potential measures for decreasing the energy consumption of schools such as lighting upgrade to LED, boiler replacements, changing electric heating to gas heating or air source pumps, pipes insulation, loft insulation. However, all these measures demand big investment that schools often cannot take loans for. To solve this problem, the ECMT prepares energy efficiency applications for schools and allocates funding through a public fund called SALIX which provides $100 \%$ interest free capital for public bodies to implement measures which helps in decreasing or controlling the energy consumption and emissions. The capital is reimbursed through yearly energy savings and once it is paid back, the schools can benefit from these financial savings. ECMT has achieved a financial saving totalling $£ 8.6$ million through these schemes. Though, these savings could not be achieved through an upgrade in technology alone. ECMT employs a human centric approach when delivering energy efficiency projects. This means that meetings are held with school managers to explain to them the necessity of upgrading their technologies, the benefits both to the environment and to their budgets, and how to use these technologies effectively to ensure meeting the expected targets of energy reduction. In many cases, these training and awareness sessions include even the pupils in order to make them aware of the energy consumption of their school, how it compares to the typical energy use of other schools and how each one of them can help in driving the energy consumption down. To demonstrate the scale of this activity, ECMT has provided around 60000 pupils with an energy education in the last 3 years.

\section{A. Water Management Challenges}

Although the ECMT puts discernible effort into energy management, little has been done for water management for different reasons. First and most importantly, water prices are very low and water budget is a small fraction of the energy prices. Therefore, there is still no financial motivation to drive the water consumption down. It should be noted that it can be extremely difficult to financially justify energy efficiency schemes particularly as ECMT procure energy at relatively low prices. Secondly, there are no funding schemes like SALIX which will encourage the schools to be on board for any water efficiency project. Third, the ECMT does not have the metering data for water consumption for the majority of schools. Thus, the water situation in schools is unknown for the energy management in the County Council and even to the schools' managers and the water supplier in some cases.

Data about energy consumption has played a big role in targeting schools which are in need for energy efficiency schemes. This data is collected via different streams: the majority of the data comes from the Automatic Meter Readings 'AMRs' via energy suppliers, some of the data comes from the business managers of the schools, other come from the invoices, and the rest come from DEC surveys. All the data is stored on SystemsLink - a software for energy monitoring and targeting- and can be accessed by all NCC employees and school business managers. Therefore, metering plays a crucial role in energy management and energy efficiency; and technologies such as AMRs or Smart Meters assist the users to actively sense and identify the energy consumption (Implementation of Smart Meter...).

The water consumption data for schools is partially 
included in SystemsLink, but incomplete for different reasons. First, sometimes it is difficult for the business managers to access the meters or even to locate them. Second, the water supplier for the County does not offer the service of supplying profile data for its customers. For the moment, the water supply is a virtual monopoly as mentioned previously; all consumers belonging to a specific region in the UK (with the exception of Scotland) has access to only one supplier excluding the very large consumers. Third, there is no legal obligation for large schools to supply water metered data on a regular basis unlike for the case of electricity where schools which fall under the profile class 00 and, in future, profile classes $05-08$ are obliged to provide half hourly data to the energy supplier. Metering and having access to this data is crucial because it gives the customers a financial incentive to save water through water efficiency saving measures; the example of households in England showed that consumption decreased by $10 \%$ upon the fitting of a meter [7].

\section{B. The Interlink of Water Management and Water Efficiency}

Despite all these challenges, ECMT has thought about different solutions to encourage a more effective management of water within the County Council and by their customers. As an example, the team has developed an innovative Water Display Certificate 'WDC' (similar to DEC) and worked with SystemsLink to develop a software solution. Nowadays, it is possible to generate WDCs for site when data is available. Another example is that the ECMT is working closely with the local water supplier company for the region to identify schools with high water consumption in order to help them in driving the consumption down.

Again, and as it is the case for the whole UK, water management and water efficiency in NCC are linked to the emissions saving targets. In fact, NCC has a corporate target of decreasing the $\mathrm{CO} 2$ emissions by $2 \%$ yearly compared to the previous year. Therefore, during the last years, different approaches, solutions and projects have been implemented in schools, NCC customers and NCC estate to decrease water and energy consumption or to use both resources efficiently. These projects are as follow: first, NCC changed, whenever it is financially feasible, decentralised water heating to point of use water heating; water is saved by lowering the possibility of leakage while distributing hot water and electricity is saved by only heating the water which will be used instantly. Second swimming pools of two schools and of the Northampton Leisure Trust have implemented, with the guidance of the ECMT, pool covers. These covers disable water evaporation and heat losses when the swimming pools are not used and thus less electricity is required for filtering and pumping water. Also, less ventilation will be needed leading to savings in heat and electricity. As an example, a pool cover installed by the ECMT in a primary school in Northamptonshire helped to decrease the school's water consumption by $15 \%$. Another example is the pool cover installed in a leisure trust's swimming pool which led to a decrease in the electricity consumption by $10 \%$. Third, showers have been installed with push button shower controls. Fourth, variable speed pumps have been used to control the flow of water. Firth, water tabs have been set up with flow restrictors to decrease the volumes of water use. Sixth and last, kettles which heat only the amount of water needed have been distributed to different organisations in Northamptonshire.

\section{CONCLUSION AND NeXT Steps}

In this paper, it has been demonstrated through the case study how energy management and water management can be interlinked. Managing water saves energy and managing energy saves water. However, water management still lacks a core structure like energy management.

In most cases and in the UK, water management is linked to energy management via the low emissions targets of organisations. Therefore, for a wide adoption of water management and water efficiency, there should be encouragement and/or enforcement from the government as it has been done for energy management. Once new regulations are enacted, all stakeholders - ranging from government agencies, standardisation bodies, funding agencies to consumers - will work together to make this practice wide-spread. Costumers will be more willing to endorse water management if they are obliged to adopt water efficiency by a set of regulation and statutory requirements, or/and got funding in the form of grants or loans with ease of access, or/and can quantify their usage and have access to their consumption data, and/or have access to training and knowledge databases for water and energy efficiency; this can be in the form of courses or standards or public engagement of different types of organisations.

However, it is believed that the non-domestic water market deregulation in 2017 in England will be the turning point for water management and water efficiency. "The government is currently reviewing its policy for setting targets for water consumption. It is only a matter of time before mandatory regulations are introduced" [19].

Last, the question that is emerging with the last regional political developments is the following: would the Britain exit from the European Union 'EU' have any effect on energy management and any future water management agenda in UK, knowing that most of the energy efficiency regulations and laws have been enacted by the EU?

\section{REFERENCES}

[1] P. A. Malinowski, A. S. Stillwell, J. S. Wu, and P. M. Schwarz. (2015). Energy-Water Nexus : Potential Energy Savings and Implications for Sustainable Integrated Water Management in Urban Areas from Rainwater Harvesting and Gray-Water Reuse. American Society of Civil Engineers. [Online]. 141(12), 1-10. Available: http://doi.org/10.1061/(ASCE)WR.1943-5452.0000528

[2] US Department of Energy. (2014). The Water-Energy Nexus: Challenges and Opportunities. [Online]. Available: http://energy.gov/sites/prod/files/2014/07/f17/Water Energy Nexus Full Report July 2014.pdf

[3] I. Ajiero and D. Campbell, "Water-energy nexus, problems and prospects for the UK," in Proc. Water Efficiency Conference 2014, pp. $1-17$.

[4] C. Ainger et al. (2009). A low carbon water industry in 2050 protecting and improving the environment in England and Bristol. [Online] Available:

https://www.gov.uk/government/uploads/system/uploads/attachment data/file/291635/scho1209brob-e-e.pdf

[5] Royal Geographical Society (with IBG). (2012). Water policy in the UK: The Challenges. [Online]. Available: 
https://www.rgs.org/NR/rdonlyres/4D9A57E4-A053-47DC-9A76-BD BEF0EA0F5C/0/RGSIBGPolicyDocumentWater_732pp.pdf

[6] HM Government Department for Environment Food and Rural Affairs, Future Water: The Government's Water Strategy for England, 2008.

[7] D. H. Le and W. Pora, (2014). "Implementation of smart meter working as IEEE1888-6LoWPAN gateway for the building energy management systems," in Proc. 2014 11th International Conference on Electrical Engineering/Electronics, Computer, Telecommunications and Information Technology, 2014, p. 5.

[8] D. Lee and C.-C. Cheng, "Energy savings by energy management systems: A review," Renewable and Sustainable Energy Reviews, vol. 56, pp. 760-777, 2016.

[9] Risser, R. (2014). ISO5001: Energy Management System. [Online]. Available:

https://www.iea.org/media/workshops/2010/emakworkshop2/9ROLA NDRISSER_USDOE.pdf

[10] The National Archives. (2014). The Energy Savings Opportunity Scheme Regulations 2014. [Online]. Available: http://www.legislation.gov.uk/uksi/2014/1643/introduction/made

[11] J. Hopkins, "The carbon reduction commitment energy efficiency scheme: Overview, rationale and future challenges," Environmental Law Review, vol. 12, no. 3, pp. 211-216, 2010.

[12] HM Government Department of Energy \& Climate Change. (2013). Energy Savings Opportunity Scheme (ESOS). [Online]. Available: https://www.gov.uk/government/uploads/system/uploads/attachment data/file/211977/20130708 - ESOS Consultation Document FINA L.pdf

[13] K. Oung, Energy Management in Business: The Manager's Guide to Maximising and Sustaining Energy Reduction, Oxon: Routledge, 2016.

[14] BSI, Energy Management Principles and Practice: A Companion to BS EN 16001:2009, London: BSI, 2009.

[15] HM Government Department for Food Environment and Rural Affairs. (2013). Water Bill The structure and regulation of the water industry. [Online].

Available: https://www.gov.uk/government/uploads/system/uploads/attachment data/file/259664/pb14058-water-bill-industry-structure-regulation.pd

[16] D. Mckibbin. (2014). An examination of business models within the Water and Sewerage Industry in the UK and Republic of Ireland. [Online]. Available: http://www.niassembly.gov.uk/globalassets/Documents/RaISe/Public ations/2014/Regional/10514.pdf

[17] Audit Scotland. (2005). Overview of the water industry in Scotland. [Online]. Available: http://www.audit-scotland.gov.uk/docs/central/2005/nr_051013_wate r_overview.pdf

[18] Water Industry Commission for Scotland. Competition in the Scottish water industry 2009-10. [Online]. Available: http://www.watercommission.co.uk/UserFiles/Documents/Competitio $n$ report - final.pdf

[19] R. Gupta, S. Chandiwala, and D. Santana, "Conserving Water in Further Education Colleges," 2007.

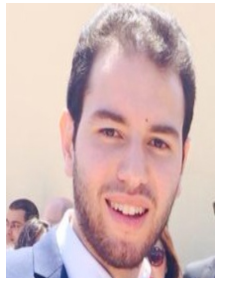

Marouane Azennoud was born in Morocco in 1990 Mr. Azennoud has a bachelor degree of science in engineering and management with Cum Laude from Al Akhawayn University in Ifrane in 2011, Ifrane, Morocco; a master of science degree in sustainable energy management from Al Akhawayn University in Ifrane in 2014, Ifrane, Morocco; and a master of engineering in international material flow management in 2014 from the Trier University of Applied Sciences in 2014, Birkenfeld, Germany.

He is currently the Smart City Programme Manager for Northamptonshire County Council, Northampton, United Kingdom. He has published a paper: R. Bull and M. Azennoud, "Smart participation- social learning: a model of participation," Energy - Proceedings of ICE, 2016
Mr. Azennoud is a lead auditor for ISO50001:2011 and is certified with Prince 2 practicioner.

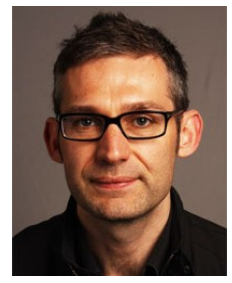

Richard Bull has a BA (hons) and a masters degree in theology at the London School of Theology, United Kingdom. He also has a PhD from the University of Birmingham, United Kingdom.

$\mathrm{He}$ is a Reader in Energy \& Behaviour Change at the Institute of Energy and Sustainable Development in De Montfort University. Over the last few years he has led a range of innovative research projects exploring the use of energy in non-domestic buildings including three JISC funded projects using ICT as an enabler for behaviour change, one of which, Greenview, went on to win the EAUC Green Gown award for Green ICT. In 2013, he was awarded £183k from the EPSRC's 'Research in the Wild' digital economy call to fund Gooddeeds, which utilized digital technologies to facilitate behaviour change through engaging and empowering employees, to reduce the environmental impact of public buildings. $\mathrm{He}$ is currently PI on an IEE EU project SAVES (http://saves.nus.org.uk) with the National Union of Students, looking at the role of energy dashboards in reducing energy consumption on Universities across Europe. He is also an expert advisor on the H2020 Smart Cities project Remourban (http://www.remourban.eu). Current research interests are around organizational factors in non-domestic energy use and citizen engagement in buildings and smart cities. He is also Associate Head of the School of Engineering and Sustainable Development.

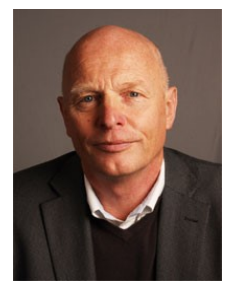

Mark Lemon had a BA (Hons) from Sussex University in 1973 in United Kingdom. He also had a $\mathrm{PhD}$ from Cranfield Instituteof Technology in 1991, United Kingdom. He is a Professor of Integrated Environmental Systems, Institute of Energy and Sustainable Development, De Montfort University, UK. Mark is a social scientist who specializes in adopting a 'whole systems' approach to action research and teaching related to the sustainability of the built environment. Within this broad area he has focused on the factors that influence organizational culture, knowledge management, and the way that multi-disciplinary and multi-agency teams define and respond to a wide range of environmental problems.

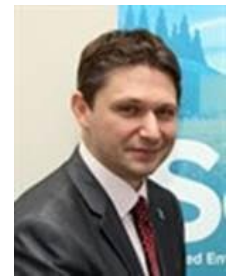

Darren Perry was born in England in 1974. Dr. Perry has a bachelor of engineering degree with honors in manufacturing engineering from Nottingham Trent University in 1996, a master of science degree in engineering business management from the University of Warwick in 1998, Warwick, United Kingdom, and a engineering doctorate from the University of Manchester in 2004, Manchester, United Kingdom.

He is currently the Head of Energy \& Carbon Management, he is directly responsible for all energy and carbon activities for Northamptonshire County Council. Over the last 7 years, he has designed, setup and managed a unique, highly innovative consultancy unit which provides a high quality customer focused energy service. The services provided fulfil statutory requirements, make money, create local investment and help to tackle fuel poverty while saving millions of pounds. His background is in industrial and property asset management supported by an engineering doctorate in maintenance engineering from the University of Manchester. Presently, he is exploring how the concept of Smart Cities can be used and applied throughout Northamptonshire.

Dr. Perry is a member of the Energy Managers Association. He is also a lead assessor for the Energy Savings Opportunity Scheme and a lead auditor for ISO50001: 2011. 

New Energy Applications 
